\title{
Drug Interaction with Radiopharmaceuticals: a Review
}

\author{
Mario Bernardo-Filho ${ }^{1,2}$, Sebastião David Santos-Filho ${ }^{1,3}$, Egberto Gaspar de Moura ${ }^{1}$, \\ Adalgisa Ieda Maiworm ${ }^{1,4}$, Margarida Maria de Camões Orlando ${ }^{5}$, Maria Expósito Penas ${ }^{6}$, \\ Valbert Nascimento Cardoso ${ }^{7}$, Luciana Camargo Bernardo ${ }^{1}$ and Lavínia de Carvalho \\ Brito ${ }^{1}$ \\ ${ }^{1}$ Universidade do Estado do Rio de Janeiro; Instituto de Biologia Roberto Alcantara Gomes; Departamento de \\ Biofísica e Biometria; Av. 28 de setembro, 87; 20551-030; Rio de Janeiro - RJ - Brasil. ${ }^{2}$ Instituto Nacional do \\ Câncer; Coordenadoria de Pesquisa; Praça Cruz Vermelha 23; 20230-130; Rio de Janeiro - RJ - Brasil. ${ }^{3}$ Centro \\ Universitário de Volta Redonda; Departamento de Ciências Biomédicas; Av. Paulo Erlei Alves Abrantes, 1325; \\ 27251-970; Volta Redonda - RJ - Brasil. ${ }^{4}$ UERJ, Hospital Universitário Pedro Ernesto; Setor de Fisioterapia; \\ ${ }^{5}$ Setor de Medicina Nuclear; Av. 28 de setembro, 87; 20551-030; Rio de Janeiro - RJ - Brasil. ${ }^{6}$ Universidade \\ Federal do Rio de Janeiro; Hospital Clementino Fraga Filho; Setor de Medicina Nuclear; Av. Brigadeiro \\ Trompowsky, s/n; 21945-560; Rio de Janeiro - RJ - Brasil. ${ }^{7}$ Universidade Federal de Minas Gerais; Faculdade de \\ Farmácia; Laboratório de Radioisótopos; Av. Antônio Carlos, 6627; 31270-901; Belo Horizonte - MG - Brasil
}

\begin{abstract}
Clinical images are worthwhile in Health Sciences and their analysis and correct interpretation aid the professionals, such as physicians, physiotherapists and occupational therapists, to make decisions and take subsequent therapeutic and/or rehabilitation measures. Other factors, besides the state of the disease, may interfere and affect the bioavailability of the radiopharmaceuticals (radiobiocomplexes) and the quality of the SPECT and PET images. Furthermore, the labeling of some of these radiobiocomplexes, such as plasma proteins, white blood cells and red blood cells, with ${ }^{99 m} T$, can also be modified. These factors include drugs (synthetic and natural) and dietary conditions, as well as some medical procedures (invasive or non-invasive), such as radiation therapy, surgical procedures, prostheses, cardioversion, intubation, chemoperfusion, external massage, immunotherapy, blood transfusion and hemodialysis. In conclusion, the knowledge about these factors capable of interfering with the bioavailability of the radiobiocomplexes is worthwhile for secure diagnosis. Moreover, the development of biological models to study these phenomena is highly relevant and desirable.
\end{abstract}

Key words: Drug interaction, blood constituents, radiobiocomplexes, bioavailability

\section{INTRODUCTION}

Clinical images are useful in the Health Sciences and their analysis and the correct interpretation aid the professionals, such as physicians, physiotherapists and occupational therapists, to make important decisions and take subsequent therapeutic and/or rehabilitation actions. The clinical procedures for obtaining images used in nuclear medicine, are normally associated with a low radiation dose level for the patient and for the staff when compared with similar procedures using $\mathrm{X}$ rays. In addition, the environmental impact is negligible due to the half life of the main radionuclides and the emission energy of the radiation commonly used in nuclear medical

\footnotetext{
* Author for correspondence
} 
procedures. The high quality of the scintigraphic images in the single photon emission computed tomography (SPECT) and in the positron emission tomography (PET) has aided in a rapid and efficient elucidation of the diagnosis of various diseases or the condition of a patient in a rehabilitation program (Carlsson, 1995, Perkins and Frier, 1999, Saha, 2004, Backer and Thierens, 2005).

SPECT and PET techniques use radiopharmaceuticals (radiobiocomplexes) to study the blood flow, the metabolism and the morphology of a biological target (system, organ or specific tissues) (Carlsson, 1995; Chandra, 1998). These radiobiocomplexes can also potentially be used to evaluate the drug formulation and the drug delivery systems (Perkins and Frier, 1999). Unexpected patterns of the bioavailability of the radiobiocomplex can normally be associated with a disease and this fact aids in the decision about a clinical diagnosis (Hladik III et al, 1987).

The development of suitable radionuclides for labeling different radiobiocomplexes to be used in the therapeutic technique has permitted reaching the target to be irradiated with great security and with negligible irradiation of the tissues in the neighborhood of the target (Owunwanne et al, 1995, Harbert et al, 1996).

Although the great relevance of nuclear medicine is well characterized, some authors have reported that other factors, in addition to the disease, can interfere in the bioavailability of a radiobiocomplex. The lackof knowledge of these factors is undesirable, and the consequences are (i) the possibility of misdiagnosis (misleading information that can either mask or mimic certain disease symptoms) and/or (ii) the repetition of the examination with an increase in radiation dose to the patient (Hladik III et al, 1987, Sampson, 1999).

\section{Factors that can alter the bioavailability of radiobiocomplexes}

Factors, other than the state of the disease, that could interfere and also affect the bioavailability of the radiobiocomplexes (Hladik III et al., 1987; Hesslewood and Leung, 1994; Gomes et al., 2002a) are presented in Fig. 1.

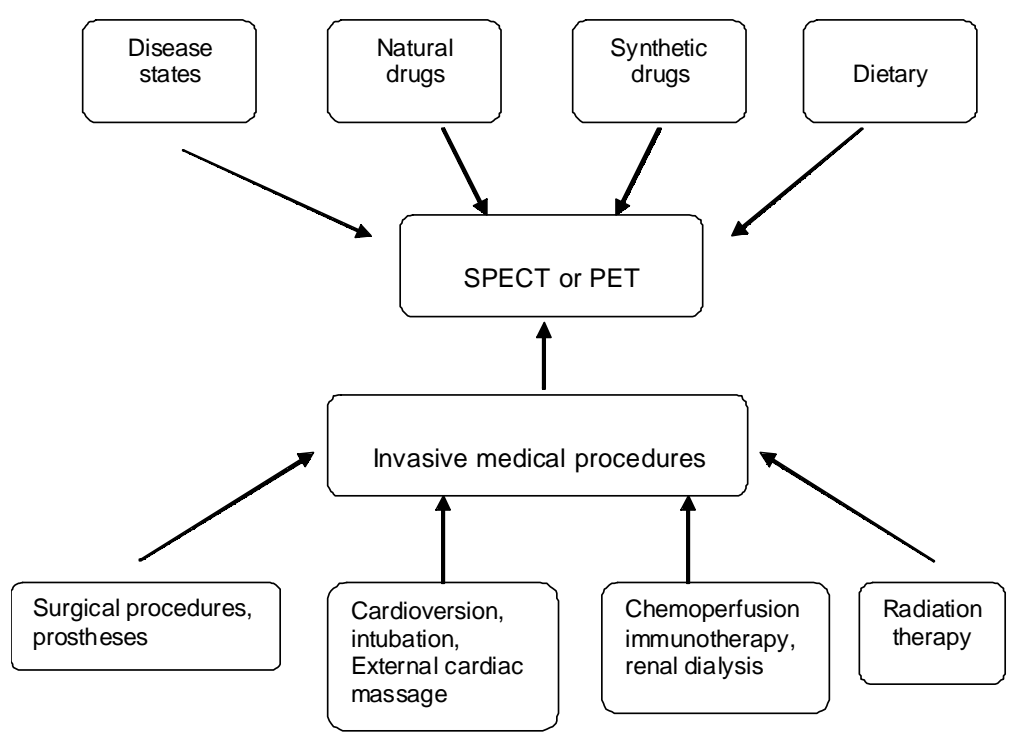

Figure 1 - Factors that can alter the bioavailability of radiobiocomplexes 
Furthermore, the labeling of some of these radiobiocomplexes, such as plasma proteins, white blood cells and red blood cells, with technetium-99m $\left({ }^{99 \mathrm{~m}} \mathrm{Tc}\right)$ can also be altered (Sampson, 1999, Gomes et al, 2002a).
The influence of these factors on the radiobiocomplex and/or in the milieu in which this labeled complex is present could lead to several undesirable consequences as shown in Table 1.

Table 1 - Undesirable conditions due to the influence of factors capable of altering the bioavailability of radiobiocomplexes

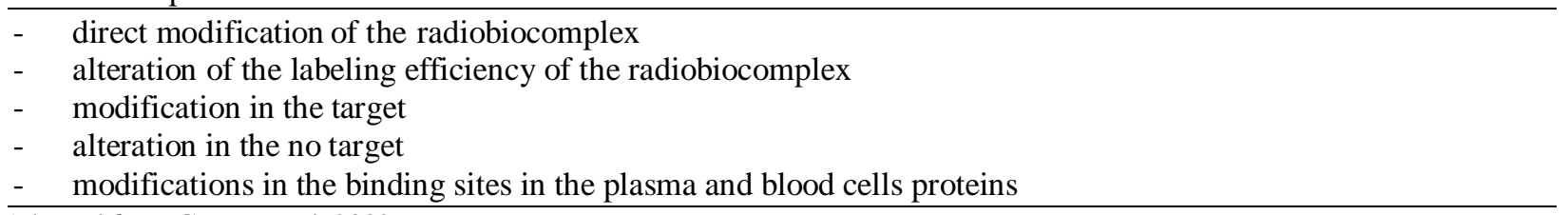
Adapted from Gomes et al, 2002a.

When a factor modifies, directly or indirectly (by the generation of free radicals), the nature of the radiobiocomplex and/or the biochemical and physiological milieu to which the referred radiotracer is exposed and/or the cellular structures of the tissue (target), the consequence may be an unexpected behavior of the radiobiocomplex (Hlakik III et al, 1987, Owunwanne et al, 1995, Gomes et al, 2002a).

\section{Diseases and the drug interaction with radiopharmaceuticals}

\section{Desirable drug interaction and the bioavailability of radiopharmaceuticals}

Among the factors indicated in Fig. 1, in addition to the diseases, the drug interaction with radiobiocomplexes (DIR) has been studied by several authors and can be known or unknown. When the DIR is known, this phenomenon can be successfully used in certain examinations with pharmacological intervention, such s (a) dypyridamole, adenosine and dobutamine in cardiac evaluations, (b) acetazolamide in brain imaging, (c) furosemide for evaluations of obstructive uropathy, (d) captopril in the studies of vovascular hypertension and (e) cholecystokinin in the hepatobiliary evaluations for confirming chronic acalculous biliary disease by determining the maximal response of the bladder to exogenous cholescystokinin measured as the ejection fraction (Owunwanne et al., 1995, Gomes et 2002a).

\section{Undesirable drug interaction and the bioavailability of radiopharmaceuticals}

Unexpected patterns of the radiobiocomplex bioavailability provoke a flurry of inquiries regarding the quality of the administered agent; however, these alterations in bioavailability may be related to the undesirable DIR. Hladik III et al. (1987), Hesslewood and Leung (1994) and Sampson (1999) have reported that various synthetic drugs (medications) are capable of altering the bioavailability of different radiobiocomplexes. Moreover, other authors have suggested that medicinal plants (natural drugs) can be also associated with the DIR (Gomes et al, 2002a, Santos-Filho et al, 2004a, Moreno et al, 2004).

Vincristine is a chemotherapeutic drug used in several protocols in oncology and (i) in an animal model, this drug has increased significantly the uptake of the radiobiocomplex ${ }^{99 \mathrm{~m}}$ Tc-DTPA (diethylenetriaminepentaacetic acid) by the thymus, ovary, uterus, spleen, kidneys, heart, stomach, lungs, liver and bone (Britto et al., 1998), (ii) it modified the bioavailability of the ${ }^{99 \mathrm{~m}} \mathrm{Tc}$-phytate in Balb/c mice (Mattos et al, 1999a), (iii) it decreased the uptake of ${ }^{99 \mathrm{~m}} \mathrm{Tc}-\mathrm{MDP}$ (methylenediphosphonic acid) by the uterus, ovary, spleen, thymus, lymph nodes (inguinal and mesentheric), kidney, liver, pancreas, stomach, heart, brain and bone isolated from animals (Mattos et al., 1999b), (iv) it decreased the uptake of ${ }^{99 \mathrm{~m}} \mathrm{Tc}-\mathrm{PYP}$ (sodium pyrophosphate) by the spleen, thymus, lymph nodes (inguinal and mesentheric), kidney, lung, liver, pancreas, stomach, heart and brain, and it 
increased the uptake by the bone and thyroid in the treated animals (Mattos et al., 1999b), (v) it decreased the uptake of the ${ }^{99 \mathrm{~m}} \mathrm{Tc}-\mathrm{GHA}$ (glucoheptonic acid) by the uterus, ovary, spleen, thymus, lymph nodes (inguinal and mesentheric), kidney and heart isolated from animals (Mattos et al., 2001), and (vi) it increased the blood pool of the radioactivity of Ga-67 citrate (Hladik III et al., 1987).

In experiments with mice, mitomycin-C (i) increased the uptake of ${ }^{99 \mathrm{~m}} \mathrm{Tc}-\mathrm{MDP}$ in thymus, ovary, uterus, heart, stomach, pancreas, kidneys, spleen and lungs (Gomes et al., 1998), (ii) altered the uptake of radiobiocomplexes used for renal evaluations (Gomes et al., 2001), (iii) modified the bioavailability of ${ }^{99 \mathrm{~m}}$ Tc-PYP (Gomes et al, 2002b) and (iv) interfered in the bioavailability of the ${ }^{99 \mathrm{~m}} \mathrm{Tc}$-phytic acid (Gomes et al., 2002c)

Buchsbaum et al, 1992 have reported PET studies of drug interaction with brain regional glucose metabolism. Kumakura et al (2004) have used the PET with parametric mapping to measure the effect of levodopa on the net clearance of $\left({ }^{18} \mathrm{~F}\right.$-fluor-fluorodopa to brain $(\mathrm{K}$, $\mathrm{ml} / \mathrm{g} / \mathrm{min}$ ). Levodopa increased the magnitude of the net clearance of $\mathrm{K}$ in the left and right putamen of healthy volunteers by $11 \%$ relative to the baseline condition. In contrast, resumption of medication with levodopa did not significantly alter the magnitude of $\mathrm{K}$ in putamen of the Parkinson's disease patients. Compartmental analysis was used to probe the physiological basis of the activation of $\mathrm{K}$ : levodopa treatment increased the apparent distribution volume of ${ }^{18} \mathrm{~F}$-fluorodopa in cerebellum of both patients and control subjects by $15 \%$, without significantly altering the unidirectional bloodbrain clearance or the relative activity of DOPA decarboxylase in putamen. It was concluded that levodopa increased the distribution volume of ${ }^{18} \mathrm{~F}$-fluorodopa in the brain, increasing its availability for utilization in dopamine terminals. Chen et al. (1994) have reported that, because of its nephrotoxicity, gentamicin may cause abnormal renal uptake to be seen in ${ }^{99 \mathrm{~m}} \mathrm{Tc}-\mathrm{MDP}$ bone scintigraphy and the presence of the radiobiocomplex in the kidneys, along with an increase in renal retention. Santos et al. (1995), in in vivo studies, have demonstrated that cyclophosphamide is capable of altering the effective half-life of the radiopharmaceuticals ${ }^{99 \mathrm{~m}} \mathrm{Tc}-\mathrm{MDP}$ and ${ }^{99 \mathrm{~m}} \mathrm{Tc}$-pertechnetate.
Valença et al. (2005) have investigated the biodistribution of $\mathrm{Na} 99 \mathrm{mTcO} 4\left(\mathrm{Na}^{99 \mathrm{~m}} \mathrm{TcO}_{4}\right)$ in mice exposed to cigarette smoke. BALB/c male mice were exposed to the smoke of nine whole commercial cigarettes per day, three times per day, for up to 10 days with whole body exposure in a chamber. A control group was shamsmoked. One day later, the exposed and control groups of mice received $7.4 \mathrm{MBq} / 0.3 \mathrm{ml}$ of $\mathrm{Na}^{99 \mathrm{~m}} \mathrm{TcO}_{4}$ and were sacrifieced after 30 minutes Bones, brain, heart, intestine, kidney, liver, lungs, muscle, pancreas, spleen, stomach, testis and thyroid were weighed and the radioactivity of these organs and the blood was recorded with a gamma counter. The percentage of injected dose per gram of tissue $(\% \mathrm{ID} / \mathrm{g})$ was determined for each organ. Cigarette smoke significantly decreased the $\% \mathrm{ID} / \mathrm{g}$ in red blood cells, bone, kidney, lung, spleen, stomach, testis and thyroid of the exposed mice.

Jankovic and Djokic (2005) have investigated the influence of the sodium methotrexate and cyclophosphamide on the organ uptake of the radiobiocomplexes, ${ }^{99 \mathrm{~m}} \mathrm{Tc}$-2,3-dicarboxypropane1,1-diphosphonic acid $\quad\left({ }^{99 \mathrm{~m}} \mathrm{Tc}-\mathrm{DPD}\right),{ }^{99 \mathrm{~m}} \mathrm{Tc}-$ meso-2,3-dimercaptosuccinic acid $\quad{ }^{99 \mathrm{~m}} \mathrm{Tc}-$ DMSA), ${ }^{99 \mathrm{~m}} \mathrm{Tc}-\mathrm{Sn}$ colloid and ${ }^{99 \mathrm{~m}} \mathrm{Tc}-$ macroaggregated albumin $\left({ }^{99 \mathrm{~m}} \mathrm{Tc}-\mathrm{MAA}\right)$ in two groups of healthy male Wistar rats treated (oral application) for 7 days. On the eighth day, each radiobiocomplex was administered to the animals. They were sacrificed at different time intervals and the radioactivity in the organs of interest was measured. The organ uptake of the radiobiocomplexes in an additional control group of animals was also studied. The results obtained showed an alteration in the organ uptake of radiobiocomplexes in the animals treated with cytotoxic drugs. In rats treated with sodium methotrexate, there was a higher uptake of ${ }^{99 \mathrm{~m}}$ Tc-DMSA by the bones, stomach and intestine, a higher uptake of ${ }^{99 \mathrm{~m}} \mathrm{Tc}-\mathrm{DPD}$ by the bones, intestine, blood and muscle, a lower uptake of ${ }^{99 \mathrm{~m}} \mathrm{Tc}-\mathrm{Sn}$ colloid by the liver and a lower accumulation of ${ }^{99 \mathrm{~m}} \mathrm{Tc}$-MAA in the lungs. Cyclophosphamide-treated animals showed enhanced uptake of ${ }^{99 \mathrm{~m}} \mathrm{Tc}$-DMSA by the kidneys, a twofold enhanced uptake of ${ }^{99 \mathrm{~m}} \mathrm{Tc}-\mathrm{DPD}$ by all organs except the stomach, a decreased uptake of ${ }^{99 \mathrm{~m}} \mathrm{Tc}-\mathrm{Sn}$ colloid by the lungs, spleen and kidneys and a significantly decreased uptake of $99 \mathrm{mTc}-\mathrm{MAA}$ by the lungs. 
The effects of extracts of various medicinal plants have been studied and (i) Santos-Filho et al, 2004 have reported that when an animal is treated for seven days with Mentha crispa by an intragastric route, the bioavailability of the $\mathrm{Na}^{99 \mathrm{~m}} \mathrm{TcO}_{4}$ is altered and there is an increase of the radioactivity in the thyroid; (ii) Santos-Filho and Bernardo-Filho (2005) have demonstrated that Hypericum perforatum decreases the bioavailability of the $\mathrm{Na}^{99 \mathrm{~m}} \mathrm{TcO}_{4}$ in the bone, muscle and thyroid and increases the bioavailability in the pancreas, (iii) Moreno et al. (2004) have verified that the Ginkgo biloba alters the bioavailability of $\mathrm{Na}^{99 \mathrm{~m}} \mathrm{TcO}_{4}$ in rats.

\section{Dietary conditions and the bioavailability of radiobiocomplexes}

Passos et al. (2000) and Passos et al. (2002) have also demonstrated that dietary conditions can also interfere with the bioavailability of radiobiocomplexes. Passos et al (2000) have studied the bioavailability of the radiobiocomplex $\mathrm{Na}^{99 \mathrm{~m}} \mathrm{TcO}_{4}$ in two rat models of malnutrition. Three groups of rats (two-monthold) were separated according to their diets: (1) control diet, $23 \%$ protein (C); (2) proteinrestricted, receiving $8 \%$ protein (PR), both ad libitum; and (3) energy-restricted, receiving $60 \%$ of the control diet (ER). After 21 days of the diet, the radiobiocomplex was injected and the animals were scrificed after $30 \mathrm{~min}$. The percentage of the injected dose (\%ID) and the $\%$ ID per gram $(\% \mathrm{ID} / \mathrm{g})$ were calculated and presented a similar pattern, increasing in the stomach and brain and decreasing in the thyroid, but without significant change in the kidney, lung, liver, bone or testis in PR rats. An increase in the $\% \mathrm{ID} / \mathrm{g}$ was only observed in the heart. In the ER group the $\% \mathrm{ID} / \mathrm{g}$ decreased only in the bone and did not change in the other organs. In another work, Passos et al. (2002) demonstrated that the $\mathrm{Na}^{99 \mathrm{~m}} \mathrm{TcO}_{4}$ biodistribution changes in malnourished adult rats whose mothers were malnourished during lactation. On the first day of lactation, the mothers were separated into three groups, C, PR and ER. After weaning, all pups received a control diet up to 60 days, when $\mathrm{Na}^{99 \mathrm{~m}} \mathrm{TcO}_{4}$ was injected and the rats were sacrificed after $30 \mathrm{~min}$. The \%ID and the \%ID/g in the thyroid, stomach, heart, bone, kidney, lung, liver, brain, and testes were evaluated. In the PR group, the \%ID and \%ID/g were significantly higher in the stomach and lower in the thyroid than in the $\mathrm{C}$ group. In the ER pups, the \%ID and \% ID/g were higher in the liver, stomach, and testes than in the $\mathrm{C}$ group. The mother's nutritional status during lactation affected the bioavailavility of the studied radiobiocomplex in the offspring, and this condition must be considered when nuclear medicine examinations are indicated.

The type of the food seems to contribute to unexpected bioavailability of radiobiocomplex (Diré et al., 2003, Capriles et al., 2002). Capriles et al. (2002) have studied the effect of eggplant extract on the biodistribution of $\mathrm{Na}^{99 \mathrm{~m}} \mathrm{TcO}_{4}$ in Wistar rats that were treated with eggplant extract in drinking water $(300 \mathrm{mg} / \mathrm{ml})$ for four weeks. ${ }^{99 \mathrm{~m}} \mathrm{Tc}$ was administered to the rats; after $90 \mathrm{~min}$ they were sacrificed and organs and blood were isolated. The \%ID increased in the liver, while the radiobiocomplex uptake was not modified in the other organs. It is suggested that, since eggplant is metabolized in the liver, this fact could justify the alteration of the uptake in this organ. Diré et al. (2003) have studied the influence of chayotte (Sechium edule) extracts (decoct and macerated) on the bioavailability of $\mathrm{Na}^{99 \mathrm{~m}} \mathrm{TcO}_{4}$ that was administrated to male Wistar rats which had or had not drunk the extract (macerated) for 60 days. After $10 \mathrm{~min}$, the animals were sacrificed, the organs were isolated, the radioactivity was determined in a well counter, and the \% ID/g was calculated. The $\% \mathrm{ID} / \mathrm{g}$ was altered in the thyroid, lung, stomach and blood. It was suggested that the generation of reactive metabolites could justify the alteration the uptake of the radiobiocomplex by specific organs.

\section{Effects of invasive medical procedures in the bioavailability of radiobiocomplexes}

\footnotetext{
Radiation therapy, surgical procedures, prostheses, cardioversion, intubation, chemoperfusion, external cardiac massage, immunotherapy, blood transfusion and renal dialysis are some invasive medical procedures in which those authors have reported alterations in the in vivo behavior of radiobiocomplexes and the quality of the nuclear medicine images (Hladik III et al., 1987, Hesslewood and Leung, 1994, Owunwanne et al., 1995, Sampson, 1999, Kumakura et al., 2004).
} 
The analysis of the effects of the radiation is very complex. However, some alterations have been reported in organs after radiation therapy, such as acute inflammatory responses, late vascular change with obliteration of the vascular bed and healing, including fibrosis, damage and cellular death. These effects are dependent on the radiation dose (type and/or fractionation), volume of the irradiated target and non-target tissue, and mitotic activity and degree of specialization of the exposed cells. Soin et al. (1977) have described the uptake of ${ }^{99 \mathrm{~m}}$ Tc-PYP by hearts of a group of patients without clinical cardiac disease who had received left chest wall irradiation. Lutrin and Goris (1979), working with $99 \mathrm{mTc}$-pyrophsphate, and Wistow et al. (1979), working with ${ }^{99 \mathrm{~m}} \mathrm{Tc}-\mathrm{MDP}$, have described an increase in the renal uptake of these radiobiocomplexes due to the radiation. Sorkin et al. (1978) have demonstrated a reduction in the uptake of ${ }^{99 \mathrm{~m}} \mathrm{Tc}$-PYP by normal irradiated bone. Gonzalez-Villalpando et al. (1982) have observed scintigraphic abnormalities of the thyroid after irradiation of this gland. Morrison and Stewart, 1995 have reported that a patient with a history of breast cancer and known lung metastases was referred for a bone scan to investigate the cause of severe neck and right shoulder pain. The bone scan showed a massive uptake of the radiopharmaceutical ${ }^{99 \mathrm{~m}} \mathrm{Tc}-\mathrm{MDP}$ by the soft tissue surrounding the right shoulder. A review of the patient's history indicated that the patient had undergone radiation therapy of the right upper thorax and breast area 14 months previously and an acute radiation dermatitis of the proximal right arm and shoulder had developed.

Suga et al. (2001) have investigated the alteration of ${ }^{99 \mathrm{~m}} \mathrm{Tc}$-DTPA transalveolar clearance in an initial phase of radiation lung injury in dogs. The DTPA transalveolar clearance was observed to be retarded soon after irradiation and an increased alveolar surfactant may be partly responsible for this retarded DTPA clearance because the aerosolized synthetic surfactant also prolonged the clearance in non-irradiated lungs. It is suggested that a DTPA clearance test is sensitive for the early detection of radiation lung injury and seems helpful for clarifying the association of epithelial integrity changes and lung surfactant in radiation lung injury.To evaluate the correlation between functional impairment and changes in the expression pattern of immunohistochemical antibodies in the early phase of radiation-induced dysfunction of salivary glands, eight rabbits were scintigraphically examined prior to and $24 \mathrm{~h}$ after irradiation (Hakim et al,. 2004). The results demonstrated a significant alteration in the $\mathrm{Na}^{99 \mathrm{~m}} \mathrm{TcO}_{4}$ uptake by all irradiated glands. Immunohistochemical changes were correlated with the functional impairment manifested scintigraphically.

Some authors have suggested that the effects of surgical incisions on the bioavailability of the radiobiocomplexes are not only limited to the local tissue damage. Hurley (1972) has reported abnormal findings in the skull upon both brain and bone scintigrafies after craniotomy. Prostheses introduced into the body during the surgical process may cause local inflammation and interfere with the localization of the radiobiocomplex, as Jayabalan and Berry (1977) and Seo and Donoghue (1980) have reported for the ${ }^{99 \mathrm{~m}} \mathrm{Tc}$-PYP found in breast prosthesis and in prosthetic valves, respectively. Velchik et al. (1989) have performed a study with the GarrenEdwards Gastric Bubble (GEGB), which was introduced as an alternative to surgery (jaw wiring, gastrointestinal bypass and vertical banded gastroplasty) for the treatment of morbid obesity in patients who had failed behavior modification therapy or dietary management for weight reduction. Its mechanism of action is unclear and previous reports have not demonstrated any significant consistent alteration in gastric emptying (GE) as measured by radionuclide techniques. To verify the effect of the GEGB on GE, ten obese patients had solid GE scans before and five weeks after endoscopic placement of the bubble. GE scans were performed in six patients after removal. The meal consisted of $300 \mu \mathrm{Ci}{ }^{99 \mathrm{~m}} \mathrm{Tc}$-sulfur colloid in the form of a egg sandwich and deionized water. Images were obtained in the anterior and posterior projections at 15-min intervals for $1 \mathrm{hr}$ (four patients) or $2 \mathrm{hr}$ (six patients) and the \%GE was calculated. Unlike other studies involving the GEGB, adjunctive therapy in the form of dieting and behavioral modification was not employed in this study. There was a significant delay in gastric emptying at $1 \mathrm{hr}$ (pre-bubble mean $\%$ gastric retention $=46 \%$; bubble mean $=$ $57 \% ; \mathrm{n}=10$ ). After removal, the GE returned to the baseline (mean $\%$ gastric retention $=51 \% ; n$ $=6$ ). One mechanism of action of the GEGB 
may be delayed gastric emptying resulting in early satiety and decreased food intake with resultant weight loss.

Krause et al. (1995) have reported that the diagnosis of acute myocardial necrosis by means of conventional electrocardiographic criteria or the release of cardiac enzymes is often difficult or even impossible in patients with out-ofhospital cardiac arrest due to ventricular fibrillation with subsequent cardiopulmonary resuscitation including several DC countershocks. Simultaneous thallium-201 $\left({ }^{201} \mathrm{Tl}\right) /{ }^{99 \mathrm{~m}} \mathrm{Tc}-\mathrm{PYP}$ tomography was prospectively applied to patients without typical clinical or electrocardiographic signs of acute myocardial infarction within $48 \mathrm{~h}$ after successful resuscitation from out-of-hospital cardiac arrest. Scintigraphic evidence of acute necrosis was present in some patients $(40 \%)$ while increased ${ }^{99 \mathrm{~m}}$ Tc-PYP uptake by the pericardial tissue was found in other patients (42\%). It may be concluded that simultaneous ${ }^{201} \mathrm{Tl} /{ }^{99 \mathrm{~m}} \mathrm{Tc}-\mathrm{PYP}$ tomography is a valuable tool for evaluation of myocardial necrosis after cardiopulmonary resuscitation including DC countershock. Acute myocardial necrosis, as indicated by SPECT, represents a potential trigger for the occurrence of ventricular fibrillation. Therefore, ${ }^{201} \mathrm{Tl} /{ }^{99 \mathrm{~m}} \mathrm{Tc}$ PYP tomography can be recommended to guide further diagnostic and therapeutic interventions after cardiopulmonary resuscitation of patients in whom the underlying cause of the occurrence of ventricular fibrillation is obscure. Slutsky et al. (1977) have found an increased uptake of bone imaging agent $\left({ }^{99 \mathrm{~m}} \mathrm{Tc}-\mathrm{PYP}\right)$ in the tissues of the chest wall at the site of application of the electrode (defibrillation). Pugh et al. (1976) have found "false positive" ${ }^{99 \mathrm{~m}}$ Tc-PYP myocardial scintigraphies due to cardioversion. DiCola et al, 1976, have reported myocardial uptake of this same rabiocomplex following direct current transthoracic countershock.

Okudan et al. (2004) have used the ${ }^{99 \mathrm{~m}}$ Tc-DTPA aerosol inhalation SPECT to assesss the pulmonary epithelial membrane permeability and to investigate the possible application of a permeability value as an indicator of early alveolar or interstitial changes in patients with blunt chest trauma. A total of 26 patients with chest trauma were referred to the emergency department. ${ }^{99 \mathrm{~m}} \mathrm{Tc}-\mathrm{DTPA}$ aerosol inhalation SPECT was performed on the first and thirtieth days after trauma. Clearance half times (T1/2) were determined and the penetration index (PI) was calculated on the first-minute image. Significant changes were observed in radioaerosol clearance and PI. Following chest trauma, clearance of ${ }^{99 \mathrm{~m}} \mathrm{Tc}$-DTPA increased as a result of breakdown of the alveolar-capillary barrier. This increase in the epithelial permeability of the lung appears to be an early manifestation of lung disease that may lead to efficient therapy in the early phase. Hladik III et al. (1987) have reported that rib trauma commonly accompanies external cardiac massage since it is demonstrated in the bone scan with ${ }^{99 \mathrm{~m}}$ Tc-MDP. Goldfarb et al. (1979) have reported that tissues subjected to trauma by the passage of a nasograstric tube have been found to show increased extra osseous uptake of a ${ }^{99 m}$ Tc-labeled phosphate derivative.

Turranoglu et al. (2001) have developed a study to determine the effects of various resuscitation regimens on lung perfusion following resuscitation from hemorrhagic shock. Rats were divided into groups and the blood pressure, rectal temperature and lung perfusion using SPECT with a ${ }^{99 \mathrm{~m}} \mathrm{Tc}$-colloid indicator were measured. The systolic blood pressure was decreased $75 \%$ by removing blood via vein jugularis in the first three groups. Group 4 was used as the control group, and blood volume was not diminished. The first three groups were resuscitated with autologous blood containing heparine in group 1, saline in group 2, and hydroxyethyl starch (HES) 6\% in group 3. After the correction of hypovolemia, all animals were injected with $99 \mathrm{mTc}$-macroaggregated albumin $\left({ }^{99 \mathrm{~m}} \mathrm{Tc}-\mathrm{MAA}\right)$ via the penil vein and images were obtained. Compared to a control group, lung perfusion was decreased significantly in groups resuscitated with saline, and HES 6\% while perfusion was restored with autologous blood. Choy et al. (1981) have described that blood transfusion influences the stability of ${ }^{99 \mathrm{~m}} \mathrm{Tc}-\mathrm{MDP}$ and, to a lesser extent, ${ }^{99 \mathrm{~m}}$ Tc-PYP. As a consequenc,e a poor bone visualization and marked renal uptake of the ${ }^{99 \mathrm{~m}} \mathrm{Tc}$ are found. Chemoperfusion has been also observed to cause a marked increase in the uptake of a bone agent, as reported by Sorkin et al. (1977). Imumnotherapy has been employed in the treatment of cancers, and Bilgi et al. (1979) have observed that patients treated with Bacillus Calmette-Guérin (BCG) may develop a systemic granulomatosis and this granulomatosis is 
associated with changes in the biodistribution of ${ }^{67} \mathrm{Ga}$-citrate that are particularly evident as abnormal lung uptake of that radiobiocomplex.

Wolfstein et al. (1976) have reported that two patients on chronic renal hemodialysis (HD) developed acute neurologic symptoms and unusual brain scan findings, including very prominent cranial sinuses. Symptoms and scan abnormalities reverted to normal within a few days. DeGraaf et al., 1979, in a study performed to determine the sensitivity of ${ }^{99 \mathrm{~m}} \mathrm{Tc}$ hydrxyethylidene diphosphonate (HEDP) in detecting gastric calcification complicating chronic renal failure, found that the radiochemical interacted with saline and the dialysate fluid to form free $\mathrm{Na}^{99 \mathrm{~m}} \mathrm{TcO}_{4}$. This resulted in the predictable uptake of the pertechnetate by stomach, thyroid, and salivary glands. Kao et al. (2003) have reported that the hypoxaemia occurring in patients with chronic renal failure (CRF) during $\mathrm{HD}$ has long been known. Before and after regular HD, lung ventilation (LV) and alveolar permeability (AP) were measured in patients with CRF, and LV and AP were determined by ${ }^{99 \mathrm{~m}}$ Tc-DTPA radioaerosol inhalation lung SPECT as well as in normal controls. After regular HD for five hours, no significant changes in the LV images were found. Before HD, the CRF patient group had a significantly faster clearance rate than that of normal controls. Moreover, the clearance rate after HD was significantly slower than that before HD. CRF can predispose patients to LV change and AP damage. After HD, the damage to AP was significantly improved. However, after $\mathrm{HD}$, the change in LV was not significant.

\section{The labeling of blood constituents and the drug interaction}

Blood constituents labeled with ${ }^{99 \mathrm{~m}} \mathrm{Tc}$ are used in clinical nuclear medicine for several important applications, including imaging of the cardiovascular system, detection of gastrointestinal bleeding sites, splenic evaluations, volemia determination and localization of intramuscular hemangioma (Chandra, 1998; Harbert et al., 1996; Early and Sodee, 1996). The main clinical use for labeled red blood cells (RBC) lies in the provision of functional information about left ventricular contraction in the multiple gated acquisition (MUGA) cardiac study (Sampson, 1999).
Moreover, this process that involves the labeling of blood constituents with ${ }^{99 \mathrm{~m}} \mathrm{Tc}$ has been successfully used as an experimental model to assess some important biological properties of extracts of natural products (Oliveira et al., 1996, Vidal et al., 1998, Reineger et al., 1999, Oliveira et al., 2000, Diré et al., 2001, Moreno et al., 2001, Lima et al., 2002, Oliveira et al., 2002, Oliveira et al, 2003a, Diré et al, 2004, SantosFilho et al., 2004b and Santos-Filho and Bernardo-Filho, 2005.

The labeling of RBC with ${ }^{99 \mathrm{~m}} \mathrm{Tc}$ can be carried out by several techniques: (a) by a completely in vitro technique, (b) by in vivo methods, or (c) by a combination of these two, called in vitro/in vivo labeling. The labeling of $\mathrm{RBC}$ and other blood constituents with $99 \mathrm{mTc}$ requires a reducing agent and the stannous ions are frequently used for this purpose (Harbert et al., 1996; Saha, 2004).

Some authors have described that synthetic or natural products in the blood, as well as the labeling conditions (temperature, number of cells and volume of the cell suspension), can have an effect on the labeling of blood constituents with ${ }^{99 \mathrm{~m}}$ Tc (Sampson, 1993; Hojelse et al., 1994; Sampson, 1996; Sampson, 1999, Braga et al., 2000). The action of different drugs (natural and synthetic) on the labeling of blood constituents with radionuclides has been reported and various important findings of possible clinical interest have been found (Sampson, 1996; Braga et al., 2000; Spicer et al., 1999).

The mechanism of the fixation of $99 \mathrm{mTc}$ on the blood constituents has also been studied and, in the $\mathrm{RBC}$, the cited radionuclide is mainly found in the $\beta$-chain of the hemoglobin molecule (Rehani and Sharma, 1980, Bernardo-Filho, 1986; Srivastava et al., 1984; Callahan and Rabito, 1990).

Nigri et al. (2002) have evaluated, in rats, the effect of the most popular antiseizure drugs (phenobarbital, phenytoin, carbamazepine, clonazepam and valproic acid) on labeling of blood constituents with ${ }^{99 \mathrm{~m}} \mathrm{Tc}$. The analysis of the results has shown that phenobarbital $(2,000$ $\mu \mathrm{g} / \mathrm{ml})$ and clonazepam (50 $\mu \mathrm{g} / \mathrm{ml})$ have significantly reduced the RBC labeling efficiency and clonazepam $(5,50 \mu \mathrm{g} / \mathrm{ml})$ has significantly decreased the labeling of plasma proteins (PP) with ${ }^{99 \mathrm{~m}} \mathrm{Tc}$. With this in vitro assay, phenytoin, phenobarbital, carbamazepine and 
valproic acid will not interfere in the ${ }^{99 \mathrm{~m}} \mathrm{Tc}$ labeling process of RBC at the therapeutic level. Interference is displayed at higher phenobarbital concentrations $(2,000 \mu \mathrm{g} / \mathrm{ml})$. However, humans do not tolerate this concentration. On the other hand, a decreased RBC and PP labeling efficiency with ${ }^{99 \mathrm{~m}} \mathrm{Tc}$ may be expected for clonazepam at therapeutic levels.

Sampson (1996; 1999) had reported that hydralazine and methyldopa significantly decrease the labeling efficiency of blood cells, possibly through oxidation of the stannous ion present in the kit. He had also reported that other workers have shown that, if clinical doses of propanolol, verapamil, chlorothiazide or frusemide are incubated with RBC, a significant reduction in the labeling efficiency is observed. Calcium channel blockers have been implicated in unusual and interesting effects in nuclear medicine. These include increased uptake of iodine-131-meta-iodo-benzyl guanidine $\left({ }^{131} \mathrm{I}\right.$ MIBG) into tumors. It is possible that nifedipine and other calcium channel antagonist's block the uptake of stannous ion into the RBC, thus preventing proper uptake by the tracer. Sulphasalazine therapy is well established as a cause of hemolysis in patients with inflammatory bowel disease. Cephalosporins have been reported to interfere seriously with the chemistry of the red cell membrane. Other drugs listed as disrupting RBC function include cytostatics, neuroleptics, tricyclic antidepressants, omeoprazole and quinine. It is well known that the concentration of stannous ion may have a marked effect on the in vitro labeling efficiency of RBC. The same group of workers also showed that propanolol, verapamil, chlorothiazide and frusemide all produced quite significant decreases in labeling efficiency when incubated with red cells.

Lee et al. (1983) have studied the effect of two antihypertensive agents (captopril and prazosin) and of digoxin on the efficiency of ${ }^{99 \mathrm{~m}} \mathrm{Tc}$ binding to RBCs of the rat. RBCs were labeled with ${ }^{99 \mathrm{~m}} \mathrm{Tc}$ in vivo. The findings demonstrated a significant reduction of RBC tagging with ${ }^{99 \mathrm{~m}} \mathrm{Tc}$ in rats treated with prazosin and digoxin, but not with captopril. The data suggest a potential interference by patient medication with the performance of blood-pool studies. It was thought that the adverse effect with digoxin was associated with an alteration in red cell membrane transport of the tracer due to inhibition of the sodium-potassium/ATP-ase dependent pump. Cyclosporin has been mentioned earlier in connection with problems in white cell labeling. The same drug also affects the RBC, as shown by the fact that the labeling efficiency decreases (Hesslewood and Leung, 1994). Later work has revealed that the drug effect was influenced by the amount of stannous ion in the kit, and that, if the kit was altered to contain higher levels of tin, the problem disappeared (Hladik III et al., 1987). Cardoso et al. (2002), have studied the potential interference of propanolol, cyclosporine, adriamycin, and nifedipine with the in vitro labeling of RBC with ${ }^{99 \mathrm{~m}} \mathrm{Tc}$. Blood collected from healthy volunteers was incubated with different concentrations of the drugs. Two labeling methods were used. With both methods, RBC was separated by centrifugation and the labeling yield was determined. Results did not show significant differences between the labeling yield for the control group and the yield withthe different concentrations of the tested drugs. Both labeling methods are useful for the in vitro preparation of ${ }^{99 \mathrm{~m}}$ Tc-RBC. The absence of significant differences in the labeling yield indicates that in vitro interferences observed by some investigators are associated with concentrations exceeding therapeutic plasma levels.

Tatum et al. (1983) made the interesting observation that blood from patients who had previously received iodinated contrast media demonstrated a sub-optimal red cell labeling efficiency. Mean labeling efficiency decreased from 90 to $30 \%$, supposedly as a result of interference with the redox potential of the stannous ion. The authors recommended that studies using ${ }^{99 \mathrm{~m}} \mathrm{Tc}-\mathrm{RBC}$ labeling using this technique be performed prior to administration of iodinated contrast media. Moreover, this effect should be kept in mind in gastrointestinal bleeding studies performed using ${ }^{99 \mathrm{~m}} \mathrm{Tc}-\mathrm{RBC}$, as well as in cardiac imaging studies.

Other factors that can influence labeling efficiency include the clinical condition of the patient and the use of intravenous cannulas containing Teflon. In their series of patients, heparin and chemotherapeutic agents were found to have significant adverse effects. It has been postulated that heparin might compete with the red blood cell for the binding of stannous ion, and chemotherapeutic agents may cause alterations in the erythrocyte membrane. Eising 
and Sciuk (1995) obtained satisfactory in vivo labeling in patients receiving chemotherapy and overcame the problems of Teflon cannulas by using a fast injection of the stannous agents, followed by a saline flush. Spicer et al. (1999) have demonstrated that some chemotherapeutic drugs do not alter the labeling of red blood cells with ${ }^{99 \mathrm{~m}} \mathrm{Tc}$.

Vento et al., (2000) have reported various drugs capable of contributing to the direct binding of $\mathrm{Na}^{99 \mathrm{~m}} \mathrm{TcO}_{4}$ to $\mathrm{RBC}$ in vivo, such as atenolol (a beta-1 blocker), carbamazepine (an anticonvulsant), cellulose fiber, disulfiram (to treat alcoholism), fluoxetine hydrochloride (an antidepressant), lorazepam (an antianxiety and antidepressant), lubricant eyes drops, multivitamins, olanzapine (an antipsychotic), ranitidine (an $\mathrm{H}-2$ antagonist), acetaminophen (for pain), epinephrine autoinject, guanifensin/methorfan (an expectorant, supressant), hydrocortisone cream and oral magnesium/aluminum hydroxides with simethicone (an antigas agent).

\section{DISCUSSION}

The normal bioavailability and elimination pattern of a radiobiocomplex may be altered under pathophysiological conditions because of the changes in the tissues. This altered biological behavior due to diseases helps a physician to define a diagnosis of a possible disease, as well as aiding other professionals, such as physotherapists and occupational therapists, to establish a rehabilitation program for an injuried patient (Carlsson, 1995, Perkins and Frier, 1999, Backer and Thierens, 2005). However, this altered biological behavior may also be due to interferences caused by pharmacodynamic effects of drugs (synthetic or natural) and the diet. Moreover, invasive medical procedures, ssuch as radiation therapy, surgical procedures, prostheses, cardioversion, intubation, chemoperfusion, external cardiac massage or other conditions that could lead a trauma, immunotherapy, blood transfusion and renal dialysis are other factors that could modify the biodistribution of the radiobiocomplex (Hladik III et al, 1987).

Because of the importance of the DIR, the study of the models to evaluate this phenomenon is worthwhile. When the DIR is known, whether desirable or undesirable, the natural consequence is a correct diagnosis (diagnostic intervention or drug therapy monitoring). However, when is unknown, it is undesirable, and the consequences are the possibility of misdiagnosis (misleading information that can either mask or mimic certain disease symptoms) and/or the repetition of the examination with an increase in radiation dose to the patient and the professional involved with the procedure. There are possible explanations for the appearance of DIR, such as radiopharmaceutical modification, alteration of the labeling efficiency, modification of the target, modification of non-targets and the alteration of the binding of the radiopharmaceutical to the blood proteins. (Hesslewood and Leung, 1994; Owunwanne et al., 1995; Hung et al., 1996; Owunwanne et al., 1998, Gomes et al, 2002).

Concerning o the labeling of blood elements with ${ }^{99 \mathrm{~m}} \mathrm{Tc}$, the exact mechanism of the effect of natural and synthetic substances on the labeling of the RBC is not completely established. In Table 2 are listed some possibilities through which the drugs could interfere in the labeling of blood constituents with ${ }^{99 \mathrm{~m}} \mathrm{Tc}$.

Table 2 - Possible mechanisms through which the drugs could interfere on the labeling of blood constituents with ${ }^{99 \mathrm{~m}} \mathrm{Tc}$

- Direct inhibition (chelating action) of the referred ions (stannous and pertechenatate)

- Damage induced in the erythrocyte membrane with morphological and morphometric alterations

- Damage induced in the erythrocyte membrane with physiological changes

- Competition of the cited ions for the same binding sites on the blood cells

- Competition of the cited ions for the same binding sites on the plasma proteins

- Generation of free radicals that could oxidize the stannous ion

- Direct oxidation of the stannous ion. 


\section{CONCLUSION}

A variety of iatrogenic physical and other aggressions that cause identifiable changes in images (SPECT and PET) are described. The nature of these abnormalities and the profusion of isolated reports concerning them may, at first, be intimidating. Most, if not all, of these abnormalities, however, might be anticipated from an understanding of the disease processes of a particular patient, and from insight into the mechanisms of the radiobiocomplex behavior. Therefore, this review emphasizes the importance of understanding the SPECT and PET images as an aspect of the patient care and not as abstract exercises divorced from the conditions of human beings in several aspects. In conclusion, the knowledge about the DIR and the other factors capable of interfering with the bioavailability of the radiobiocomplexes is very important for secure diagnosis. In addition, the development of biological models to study this phenomenon is highly relevant and desired.

\section{ACKNOWLEDGMENTS}

The authors thank the CNPq, FAPERJ and UERJ for their support.

\section{RESUMO}

Imagens clínicas são valiosas em Ciências da Saúde e a análise e a interpretação correta das mesmas auxiliam os profissionais, como médico, fisioterapeuta, terapeuta ocupacional, na tomada de decisões e subseqüentes ações terapêuticas e/ou de reabilitação. Além das doenças outros fatores podem interferir e afetar a biodisponibilidade dos radiofármacos (radiobiocomplexos) e a qualidade das imagens (SPECT e PET). Além disso, a marcação de alguns desses radiobiocomplexos com Tc-99m, como proteínas plasmáticas, leucócitos e hemácias, também pode ser modificada. Entre esses fatores, estão drogas (sintéticas e naturais) e condições alimentares, assim como alguns procedimentos médicos (invasivos e não invasivos), como a radioterapia, processos cirúrgicos, próteses, cardioversão, intubação, quimioperfusão, massagem externa, imunoterapia, transfusão sanguínea e hemodiálise. Em conclusão, o conhecimento sobre esses efeitos capazes de interferir na biodisponibilidade de radiobiocomplexos é altamente relevante para diagnósticos precisos. Além disso, o desenvolvimento de modelos biológicos para estudar esses fenômenos é de elevada importância e desejável.

\section{REFERENCES}

Bacher, K. and Thierens, H. M. (2005), Accurate dosimetry: an essential step towards good clinical practice in nuclear medicine. Nucl. Med. Commun., 26, 581-586.

Bernardo-Filho, M.; Caniné, M. S.; Lopes, R. L. F. and Boasquevisque E. M. (1986), Effect of temperature on the "in vitro" labeling of red blood cells with technetium-99m. Arq. Biol. Tecnol., 29, 407-412.

Bilgi, C.; Brown, N. E.; McPherson, T. A. and Lentle, B. (1979). Pulmonary manifestations in patients with malignant melanoma during BCG immunotherapy. A preliminary report. Chest, $\mathbf{7 5}$, 685-687.

Braga, A. C. S.; Oliveira, M. B. N.; Feliciano, G. D.; Reiniger, I. W.; Oliveira, J. F.; Silva, C. R. and Bernardo-Filho, M. (2000), The effect of drugs on the labeling of blood elements with technetium99m. Curr Pharm Design, 6, 1179-1191.

Britto, D. M. M.; Gomes, M. L.; Rodrigues, P. C.; Paula, E. F.; Gutfilen, B. and Bernardo-Filho, M. (1998), Effect of the chemotherapeutic drugs on the biodistribution of ${ }^{99 \mathrm{~m}} \mathrm{Tc}$-DTPA in Balb/c mice. $J$. Exp. Clin. Cancer Res., 17, 313-316.

Buchsbaum, M. S.; Potkin, S.; Siegel, B.; Bunney, W. E.; Lohr, J.; Katz, M.; Gottschalk, L.; Lottenberg, S.; Teng, C. and Abel, L. (1992), PET studies of drug interaction with brain regional glucose metabolism. Clin Neuropharmacol. 15, 472A-473A.

Callahan, R. J. and Rabito, C. A. (1990), Radiolabeling of erythrocytes with technetium ${ }^{-99 m}$ : role of band-3 protein in the transport of pertechnetate across the cell membrane. J. Nucl. Med., 31, 2004-2008.

Capriles, P. V.; Dias, A. P. M.; Costa, T. E. M. M.; Oliveira, M. B. N.; Faria, M. V. C.; Moura, E. G.; Abreu, B. A. L. and Bernardo-Filho, M. (2002), Effect of eggplant (Solanum melongena) extract on the in vitro labeling of blood elements with technetium-99m and on the biodistribution of sodium pertechnetate in rats. Cell. Mol. Biol., 48, 771-776. 
Cardoso, V.; Roca, M. and Martin-Comin, J. (2002), No influence of propanolol, cyclosporine, adriamycin, and nifedipine on the in vitro labeling of erythrocytes. Rev. Esp. Med. Nucl., 21, 24-27.

Carlsson, S. (1995), A glance at the history of nuclear medicine. Acta. Oncol., 34, 1095-1102.

Chandra, R. (1998), Nuclear medicine physics, the basics. $5^{\text {th }}$ ed. New York: Williams \& Wilkins.

Chen, W. L.; Perng, M. Y.; Hwei, D. Z. and Yu, M. D. (1994), Therapeutic drug monitoring can avoid iatrogenic alterations caused by ${ }^{99 \mathrm{~m}} \mathrm{Tc}$-methylene diphosphonate (MDP)-gentamicin interaction. J. Nucl. Biol. Med., 38, 132-134.

Choy, D.; Murray, I. P. and Hoschl, R. (1981), The effect of iron on the biodistribution of bone scanning agents humans. Radiol., 140, 197-202.

DiCola, V. C.; Freedman, G. S.; Downing, S. E. and Zaret, B. L. (1976), Myocardial uptake of technetium-99m stannous pyrophosphate following direct current transthoracic countershock. Circulation., 54, 980-986.

DeGraaf, P.; Pauwels, E. K. J. and Schicht, I. M. (1979), Scintigraphy detection of gastric calcification in dialysis patients. Diagn. Imaging, 48, 171-176.

Diré, G.; Lima, E.; Mattos, D.; Oliveira, M. B.;

Pereira, M. J.; Moreno, S.; Freitas, R.; Gomes, M.

L. and Bernardo-Filho, M. (2001), Effect of

chayotte (Sechium edule) extract on the

biodistribution of technetium-99m and on the morphometry of red blood cells. J. Label. Compds.

Radiophars., 44, S648-S650.

Diré, G. F.; Honeycutt, H. P.; Gomes, M. L.; Lima, E. A. C.; Mattos, D. M. M. and Bernardo-Filho, M. (2004), An In Vivo Evaluation of an Aqueous Extract of Uncaria Tomentosa on the Morphology on the Labeling of Blood Constituents with 99mTechnetium. Nature and Science, 2, 6-10.

Diré, G.; Lima, E.; Gomes, M. and Bernardo-Filho, M. (2003), The effect of a chayote (Sechium edule) extract (decoct and macereated) on the labeling of blood elements with technetium ${ }^{-99 m}$ and on the biodistribution of the radiopharmaceutical sodium pertechnetate in mice: an in vitro and in vivo analysis. Pakistan. J. Nutrit., 2, 221-227.

Early, P. J. and Sodee, D. B. (1996), Principles and Practice of Nuclear Medicine. Toronto : Mosby Year Book Inc.

Eising, E. G. and Sciuk, J. (1995), Failure to label red blood cells adequately in daily practice using an in vivo method: methodological and clinical considerations. Eur. J. Nucl. Med., 22, 587.

Goldfarb, C. R.; Shah, P. J. and Jay, M. (1979), Extraosseous uptake of bone-seeking tracers: an expected but unsuspected addition to the list. Clin Nucl Med., 4, 194-195.
Gomes, M. L.; Braga, A. C.; Mattos, D. M.; Freitas, R. S.; Paula, E. F.; Bezerra, R. J. A. C. and Bernardo-Filho, M. (2002c), Effect of the mitomycin-C on the biodistribution of the radiopharmaceutical 99m Technetium-phytic acid in mice: a model to evaluate the toxic effect of a chemical drug. J. Appl. Toxicol., 22, 85-87.

Gomes, M. L.; Braga, A. C. S.; Mattos, D. M. M.; Freitas, R. S.; Boasquevisque, E. M. and BernardoFilho, M. (1998), Mitomycin-C effect on the biodistribution of the radiopharmaceutical technetium-99m-methylenediphosphonic acid in balb/c mice. Nucl. Med. Commun., 19, 1177-1179.

Gomes, M. L.; Mattos, D. M. M.; Freitas, R. S.; Bezerra, J. R. A. C. and Bernardo-Filho, M. (2001), Study of the toxicological effect of mitomycin $\mathrm{C}$ in mice: alteration on the biodistribution of radiopharmaceuticals used for renal evaluations. Hum. Exp. Toxicol., 20, 193-197.

Gomes, M. L.; Mattos, D. M. M.; Freitas, R. S.; Diré, G. F.; Lima, E. A. C.; Souza, S. M. S. and Bernardo-Filho, M. (2002b), Evaluation of the effect of mitomycin-C on the bioavailability of technetium $99 \mathrm{~m}$-labelled sodium pyrophosphate in mice. Cell. Mol. Biol., 48, 757-760.

Gomes, M. L.; Oliveira, M. B. N. and BernardoFilho, M. (2002a), Drug interaction with radiopharmaceuticals: effect on the labeling of red blood cells with technetium ${ }^{-99 m}$ and on the bioavailability of radiopharmaceuticals. Braz. Arch. Biol Technol., 45, 143-149.

Gonzalez-Villalpando, C.; Frohman, L. A.; Bekerman, C.; Favus, M. J.; Pinsky, S.; Ryo, U. Y.; Shore-Freedman, E. and Schneider, A. B. (1982), Scintigraphic thyroid abnormalities after radiation. A controlled study with ${ }^{99 \mathrm{~m}} \mathrm{Tc}$ pertechnetate scanning. Ann. Intern. Med., 97, 55-58.

Harbert, J. C.; Eckelman, W. C. and Neumann, R. D. (1996), Nuclear Medicine Diagnosis and therapy. New York : Thieme Medical Publishers.

Hakim, S. G.; Jacobsen, H. C. H.; Hermes, D.; Kosmehl, H.; Lauer, I.; Nadrowitz, R. and Sieg, P. (2004), Early Immunohistochemical and functional markers indicating radiation damage of the parotid gland. Clin. Oral Investig., 8, 30-35.

Hesslewood, S. and Leung, E. (1994), Drug interactions with radiopharmaceuticals. Eur. J. Nucl. Med., 21, 348-356.

Hladik III, W. B.; Saha, G. B. and Study, K. T. (1987), Essentials of Nuclear Medicine Science. London : William and Wilkins.

Hojelse, C.; Kristensen, K. and Sampson, C. B. (1994), In: Sampson, C. B. (Ed.). Textbook of Radiopharmacy - Theory and Practice. London. 
Hung, G. L.; James, A. P. and Hammes, R. J. (1996), Radiopharmaceuticals related pitfalls and artifacts. Semin. Nucl. Med., 26, 208-255.

Hurley, P. J. (1972), Patent formamen ovale demonstrated by lung scanning. J. Nucl. Med., 13, 177-179.

Jankovic, D. L. J. and Djokic, D. D. J. (2005), Alteration of the organ uptake of the $(99 \mathrm{~m}) \mathrm{Tc}$ radiopharmaceuticals, (99m)Tc-DPD, (99m)TcDMSA, (99m)Tc-tin colloid and (99m)Tc MAA, induced by the applied cytotoxic drugs methotrexate sodium and cyclophosphamide. $\mathrm{Nucl}$ Med Commun., 26, 415-419.

Jayabalan, V. and Berry, S. (1977), Accumulation of ${ }^{99 \mathrm{~m}}$ Tc-pyrophosphate in breast prothesis. Clin. Nucl. Med., 2, 452-453.

Kao, M. T.; Shiau, Y. C.; Tsai, J. J.; Wang, J. J.; Ho, S. T. and Kao, A. (2003), Evaluating the changes in alveolar permeability and lung ventilation in patients with chronic renal failure after haemodialysis using 99mTc-DTPA radioaerosol inhalation lung scan. Nucl. Med. Commun., 24, 825-828.

Kumakura, Y.; Danielsen, E. H.; Reilhac, A.; Gjedde, A. and Cumming, P. (2004), Levodopa effect on [18F]fluorodopa influx to brain: normal volunteers and patients with Parkinson's disease. Acta Neurol Scand., 110, 188-195.

Krause, T.; Hohnloser, S. H.; Kasper, W.; Schumichen, C.; Reinhardt, M. and Moser, E. (1995), Assessment of acute Myocardial necrosis after cardiopulmonary resuscitation and cardioversion by means of combined thallium $201 /$ technetium ${ }^{-99 m}$ pyrophosphate tomography. Eur. J. Nucl. Med., 22, 1286-91.

Lee, H. B.; Wexler, J. P.; Scharf, S. C. and Blaufox, M. D. (1983), Pharmacologic alterations in $\mathrm{Tc}^{-99 \mathrm{~m}}$ binding by red blood cells: concise communication. J. Nucl. Med., 24, 397-401.

Lima, E. A. C.; Diré, G.; Mattos, D. M. M.; Freitas, R.; Gomes, M. L.; Oliveira, M. B.; Faria, M. V. C.; Jales, R. L. and Bernardo-Filho, M. (2002), Effect of an extract of cauliflower (leaf) on the labeling of blood elements with technetium-99m and on the survival of Escherichia coli AB1157 submitted to the treatment with stannous chloride. Food Chem. Toxicol., 40, 919-923.

Lutrin, C. L. and Goris, M. L. (1979), Pyrophosphate retention by previously irradiated renal tissue. Radiol., 133, 207-209.
Mattos, D. M. M.; Gomes, M. L.; Freitas, R. S. and Bernardo-Filho, M. (1999a), Effect of the chemotherapeutic drugs on the biodistribution of the radiopharmaceutical ${ }^{99 \mathrm{~m}} \mathrm{Tc}$-phytate in Balb/c mice. In: Nicolini, M. and Mazzi, U. (Eds.). Technetium, Rhenium and Other Metals in Chemistry and Nuclear Medicine. Podova : Servizi Grafici Editoriali. pp. 465472.

Mattos, D. M. M.; Gomes, M. L.; Freitas, R. S.; Cardoso, V. N. and Bernardo-Filho, M. (2001), Drug interaction with radiopharmaceuticals and the importance for the radiation dose to the patient. In: IAEA (Eds.). Radiological protection of patients in diagnostic and interventional radiology, nuclear medicine and radiotherapy. Vienna, Austria.

Mattos, D. M. M.; Gomes, M. L.; Freitas, R. S.; Rodrigues, P. C.; Paula, E. F. and Bernardo-Filho, M. (1999b), A model to evaluate the biological effect of natural products: vincristine action on the biodistribution of radiopharmaceuticals in Balb/c female mice. J. Appl. Toxicol., 19, 251-254.

Moreno, S. R. F.; Feliciano, G. D.; Freitas, R. S.; Mattos, D. M.; Gomes, M. L.; Farah, M. B.; Laurentino-Filho, G.; Rocha, E. K. and BernardoFilho, M. (2001), Effect of Ginkgo biloba on the in vitro labeling of red blood cells and plasma proteins with technetium-99m. J. Label. Compd. and Radioph., 44, S639-S641.

Moreno, S.; Carvalho, J. J.; Nascimento, A. L. R.; Freitas, R. S.; Diré, G.; Lima, E.; Lima-Filho, G.; Rocha, E. K. and Bernardo-Filho, M. (2004), Biodistribution of sodium pertechnetate and light microscopy of organs isolated from the rats: study of the effects of a Ginkgo biloba extract. Pakistan Journal of Nutrition, 3, 64-67.

Morrison, R. T. and Stewart, R. D. (1995), Delayed massive soft tissue uptake of Tc-99m MDP after radiation therapy for cancer of the breast. Clin. Nucl. Med., 20, 770-771.

Nigri, F.; Oliveira, M. B. and Bernardo-Filho, M. (2002), Assessment of the effect of antiseizure drugs on the labeling process of red blood cells and plasma proteins with technetium-99m. Cell. Mol. Biol. (Noisy-le-grand), 48, 793-801.

Okudan, B.; Han, S.; Baldemir, M. and Yildiz, M. (2004), Detection of alveolar epithelial injury by 99mTc-DTPA radioaerosol inhalation lung scan following blunt chest trauma. Ann. Nucl. Med., 18, 573-577.

Oliveira, J. F.; Braga, A. C. S.; Ávila, A. S.; Fonseca, L. M. B.; Gutfilen, B. and Bernardo-Filho, M.( 1996), Effect of Thuya occidentalis on the labeling of red blood cells and plasma proteins with technetium-99m. Yale J. Biol. Med., 69, 489-494. 
Oliveira, J. F.; Braga, A. C. S.; Oliveira, M. B. N.; Ávila, A. S.; Caldeira-de-Araújo, A.; Nascimento, C. V.; Bezerra, R. J. and Bernardo-Filho, M. (2000), Effect of Maytenus ilicifolia (espinheira santa) extract on the labeling of red blood cells and plasma proteins with technetium-99m. $J$. Ethnopharmacol., 72, 179-184.

Oliveira, J. F.; Avila, A. S.; Braga, A. C. S.; Oliveira, M. B. N.; Boasquevisque, E. M.; Jales, R. L.; Cardoso, V. N. and Bernardo-Filho, M. (2002), Effect of extract of medicinal plants on the labeling of blood elements with technetium-99m and on the morphology of red blood cells: I - a study with Paullinia cupana. Fitoterapia, 73, 305-312.

Oliveira, J. F.; Oliveira, M. B. N.; Avila, A. S.; Braga, A. C. S.; Catanho, M. T. J.; Jales, R. L.; Cardoso, V. N. and Bernardo-Filho, M. (2003b), Assessment of the effect of Fucus vesiculosus extract on the labeling of blood constituents with technetium-99m and the histological modifications on the shape of the red blood cells. Food and Chemical Toxicology, 41,15-20.

Oliveira, J. F.; Santos-Filho, S. D.; Catanho, M. T. J.; Srivastava, S. C.; Lima-Filho, G. and BernardoFilho, M. (2003a), Effect of extract of medicinal plant on the labeling of blood elements with Technetium-99m and on the morphology of red blood cells (RBC): toxicological action of roast coffee beans (Coffea arabica). Indian J. Nucl. Med., 18, 52-56.

Owunwanne, A.; Patel, M. and Sadek, S. (1995), Preparation of radiopharmaceuticals. The handbook of radiopharmaceuticals. London : Chapman \& Hall.

Owunwanne, A.; Shihab-Eldeen, A.; Yacoub, T. and Ziada, G. (1998), The use of radiopharmaceuticals as an effective toxicologic technique for studying nephrotoxicity of drugs: cyclosporine-A. Hum. Exp. Toxicol., 17, 613-619.

Passos, M. C. F.; Ramos, C. F.; Bernardo-Filho, M.; Mattos, D. M. and Moura, E. G. (2000), The effect of protein or energy restriction on the biodistribution of $\mathrm{Na}^{99 \mathrm{~m}} \mathrm{TcO}_{4}$ in Wistar rats. Nucl. Med. Comm., 21, 1059-1062.

Passos, M. C. F.; Ramos, C. F.; Dutra, S. C. P.; Bernardo-Filho, M. and Moura, E.G. (2002), Biodistribution of $\mathrm{Na}^{99 \mathrm{~m}} \mathrm{TcO}_{4}$ changes in adult rats whose mothers were malnourished during lactation. J. Nucl. Med., 43, 89-91.

Perkins, A. and Frier, M. (1999), Nuclear Medicine in Pharmaceutical Research. Taylor \& Francis, London.

Pugh, B. R.; Buja, L. M.; Parkey, R. W.; Polimer, L. R, Stokely, E. M.; Bonte, F. J. and Willerson, J. T. (1976), Cardioversion and "false positive" technetium-99m stannous pyrophosphate myocardial scintigrams. Circulation., 54, 399-403.
Rehani, M. M. and Sharma, S. K. (1980), Site of Tc ${ }^{-}$ $99 \mathrm{~m}$ binding to the red blood cell: concise communication. J. Nucl. Med., 21, 676-678.

Reineger, I. W.; Oliveira, J. F.; Caldeira-de-Araújo, A. and Bernardo-Filho, M. (1999), Effect of Peumus boldus on the labeling of red blood cells and plasma proteins with technetium-99m. App. Radiat. Isot., 51, 145-149.

Saha, G. B. (2004), Fundamentals of nuclear pharmacy. New York : Springer-Verlag.

Sampson, C. B. (1993), Adverse reactions and drug interactions with radiopharmaceuticals. Drug Safety., 8, 280-294.

Sampson, C. B. (1996), Complications and difficulties in radiolabelling blood cells: A review. Nucl. Med. Comm., 17, 648-658.

Sampson, C. B. (1999), Textbook of radiopharmacy theory and practice. Amsterdam : Gordon and Breach.

Santos, J. S.; Paula, E. F.; Correa, T. G.; Freitas, L. C.; Fonseca, L. M.; Gutfilen, B. and Bernardo-Filho, M. (1995), Effect of cyclophosphamide on the binding of $99 \mathrm{mTcO}_{4}{ }^{-}$and $99 \mathrm{mTc}-\mathrm{MDP}$ to blood cells and plasma proteins. Braz. J. Med. Biol. Res., 28, 131135.

Santos-Filho, S. D. and Bernardo-Filho, M. (2005), Efeito de um extrato de Hypericum perforatum na marcação in vitro de elementos sanguíneos com tecnécio-99m e na biodisponibilidade do radiofármaco pertecnetato de sódio em ratos Wistar. Acta Cir. Bras., 20, 121-125.

Santos-Filho, S. D.; Diré, G. L.; Lima, E.; Oliveira, M. N. and Bernardo-Filho, M. (2004b), Effect of Mentha crispa (mint) extract on the labeling of blood elements with technetium-99m: a possible evaluation of free radicals. J. Biol. Sci., 4, 266-270.

Santos-Filho, S. D.; Gomes, M. L.; Diré, G. L.; Lima, E. and Bernardo-Filho, M. (2004a), Evaluation of the effect of Mentha crispa (mint) extract on the bioavailability of the radiopharmaceutical ${ }^{99 \mathrm{~m}} \mathrm{Tc}$ sodium pertechnetate in Wistar rats. World J. Nucl. Med., 3, 235.

Seo, I. and Donoghue, G. (1980), Tc-99m pyrophosphate accumulation on prothetic valves. Clin. Nucl. Med., 5, 367-369.

Slutsky, L. J.; Passalaqua, A. M. and Oster, Z. H. [19--], Uptake of ${ }^{99 \mathrm{~m}} \mathrm{Tc}$ pyrophosphate in chest wall tissues due to defibrillation. Clin. Nucl. Med., 2, 67.

Soin, J. S.; Cox, J. D.; Youker, J. E. and Swartz, H. M. (1977), Cardiac localization of ${ }^{99 \mathrm{~m}} \mathrm{Tc}-(\mathrm{Sn})-$ pyrophosphate following irradiation of the chest. Radiology, 124, 165-168.

Sorkin, S. J.; Horij, S. C. and Passalaqua, A. [19--], Augmented activity on a bone scan following local chemoperfusion. Clin. Nucl. Med., 2, 451. 
Spicer, J. A.; Hladik, W. B. and Mulberry, W. E. (1999), The effects of selected antineoplastic agents on the labeling of erythrocytes with technetium-99m using the UltraTag RBC kit. $J$. Nucl. Med. Technol., 27, 132-135.

Srivastava, S. C.; Straub, R. F. and Richards, P. (1984), Mechanistic aspects of the technetium99m-tin-RBC labeling reactions. J. Label. Comp. Radioph., 21, 1055.

Suga, K.; Alderson, P. O.; Mitra, A.; Domingues, C.; Rescigno, J.; Smith, L. G.; Ogasawara, N.; Matsunaga, N. and Sasai, K. (2001), Early retardation of $99 \mathrm{mTc}$-DTPA radioaerosol transalveolar clearance in irradiated canine lung. $J$. Nucl. Med., 42, 292-299.

Tatum, J. L.; Burke, T. S.; Hirsch, J. I.; Miller, W. W. and Fratkin, M. J. (1983), Pitfall to modified in vivo method of technetium-99m red blood cell labeling. Iodinated contrast media. Clin. Nucl. Med., 8, 585-587.

Turranoglu, S.; Kaya, S.; Kararmaz, A. and Turhanoglu, A. D. (2001), Lung perfusion in hemorrhagic shock of rats: the effects of resuscitation with whole blood, saline or Hes $6 \%$. Tohoku J. Exp. Med., 195, 245-251.
Vento, J. A.; Swing, L. S. and Spencer, R. P. (2000), Persistent binding of Tc-99m pertechnetate to erythrocytes in a patient receiving multiple pharmaceuticals. Clin. Nucl. Med., 25,152-153.

Valenca, S. S.; Lima, E. A.; Dire, G. F.; BernardoFilho, M. and Porto, L. C. (2005), Sodium pertechnetate (Na99mTcO4) biodistribution in mice exposed to cigarette smoke. BMC Nucl. Med., 11, 1 .

Velchik, M. G.; Kramer, F. M.; Stunkard, A. J. and Alavi, A. (1989), Effect of the Garren-Edwards gastric bubble on gastric emptying. J. Nucl. Med., 30, 692-6.

Vidal, M. V.; Gutfilen, B.; Barbosa-da-Fonseca, L. M. and Bernardo-Filho, M. (1998), Influence of tobacco on the labeling of red blood cells and plasma proteins with technetium ${ }^{-99 m}$. J. Exp. Clin. Cancer Res., 17, 1-6.

Wistow, B. W.; McAfee, J. G.; Sagerman, R. H.; Thomas, F. D. and Grossman, Z. D. (1979), Renal uptake of $\mathrm{Tc}^{-99 \mathrm{~m}}$ methylene diphosphonate after radiation therapy. J. Nucl. Med., 20, 32-34.

Wolfstein, R. S.; Tanasescu, D. E.; Waxman, A. D. and Siemsen, J. K. (1976), Transient brain scan abnormalities in renal dialysis patients. J. Nucl. Med., 17, 6-8. 